\title{
EXPLORING NEW VISIONS AND VIEWS OF LANGUAGE AND LITERACY
}

The six articles presented in this issue of $L 1$ - Educational Studies in Language and Literature_represent both the language and literature domains of the title. More importantly, they represent the first issue as an exclusively online journal with free access to all readers and members of the International Association for the Improvement of Mother Tongue Education.

On many levels, the six articles focus on issues of language acquisition; each celebrates language and literature in diverse, fresh and even provocative ways.

In The Influence Of Environmental Print On Preschoolers' Literacy Development In A Two-Alphabet Society, Angela Yannicopoulou presents a remarkable and unique opportunity to investigate the notion of how literacy develops in preparation for or entrance to formal literacy instruction. While, as she notes, Greek is the monolingual mother tongue language of Greece, children also experience the Roman alphabet through environmental print in their surroundings. For pre-literature children, the two language systems co-exist. To understand more clearly how this operates within the culture and literacy of young children, Yannicipoulou creates a research inquiry to determining whether kindergarten children with no formal literacy instruction can distinguish between the two very distinct alphabetic systems. In her study with 504 pre-school children, she found that, apart from the major role that visual language plays in the reading of environmental print, information about actual letters is also absorbed by preschoolers. In tapping their knowledge about written texts and literary experiences, Yannicopoulou found that when the visual modality proved inadequate to 'solve the problem,' the children turned to the written code. This research suggests that even pre-literate youngsters do not use their knowledge of letters as they read the envrironmental print, but they approach it as a whole

i

L1 - Educational Studies in Language and Literature (2006) 6(1), p i-iv

(C) International Association for the Improvement of Mother Tongue Education 
relying on graphic and visual cues. It appears that environmental print contributes to literacy development. Yannicopoulou provides a unique window into the early stages of literacy acquisition that has implications far beyond Greece and provides an impetus for inquiries into the degree to which preschoolers learn from environmental print to inform and define instructional practices. The article introduces a unique window into the complex process of how literacy develops before formal instruction in schools.

While the previous article is located in a monolingual country with two alphabetic systems operating side by side, Bezemer and Kroon, in "You Don't Need to Know the Turkish Word" Immigrant Minority Lanquage Teaching Policies and Practice in the Netherlands, take on an issue that increasingly concerns a diverse and globalized world where multiple languages and cultures intersect in schools. Effective strategies and pedagogies for children with mother tongues that vary from the dominant language of the schools and national language continue to be constructed and debated. Bezemer and Kroon undertake to demonstrate the relationship and/or disconnect between national public policy, school programs, and teacher interpretations and expectations of the curriculum and policies in the Netherlands.

To that end, they identify different versions of the language support curriculum on the basis of in-depth analyses of policy documents from the national and local governments (the formal curriculum), and the National Educational Innovation Centre for Primary Education and the Inspectorate of Education (the ideological curriculum). In a study conducted in a multicultural primary school using observations, interviews, and school documents (the perceived, operational and experiential curriculum), they analyse policies and practices related to language support. Not surprisingly, analyses revealed divergent understandings and practices derived from the policies and curricula. They also show how inaccurate assumptions of the pupils' relative command in Dutch and the minority language impact on actual practices of language support in schools.

The issue may well boil down to interpretation: What does "language support" mean to the various stakeholders? How important is shared understanding? What happens when multiple home languages exist in one classroom? Does language support homogenize diverse groups into the single category of "second language learners"? This issue is relevant beyond the Dutch borders in that in countries such as Canada, schools, particularly in the larger urban centers, may have over 50 languages represented among their students. In such complex contexts, what does "language support" mean? While the question may not be answered, Bezemer and Kroon direct our attention to a critical issue that cannot be ignored.

Braaksma, Rijlaarsdam, Van den Bergh and Van Hout-Wolters focused their study on observational learning in the article entitled, What Observational Learning Entails: A Multiple Case Study. Braaksma and her colleagues address an issue that has plagued educational research and theory for some time: How do children learn and acquire competence and proficiency in schools? The inqury of this article challenges the conception that "learning by doing" is causally linked to better learning. The authors argue that when high school students are learning to write persuasive 
(and other) texts, they can learn by observing rather than simultaneously engaging in the dual task of learning to write and actually writing. In observing, they argue, attention is given completely to learning to write.

In the case study represented in the study, six secondary students thought aloud while observing sets of writers as peer models. They observed the models' writing, identified and conceptualized the writing strategies, evaluated the performance of the models and reflected explicitly on the observed performances. Although not expected to write, students recorded their observations and learning on paper. They compared their (covert) performance with the (overt) performance of the models. They carried out (meta)cognitive activities such as observing, comparing, evaluating, and reflecting - activities assumed to play a central role in learning to write.

The study brings new perspectives to learning to write that complements and enrich the research literature on writing.

In an unusual turn, this issue includes two articles by Per Henning Uppstad. Both address theoretical positions around conceptions and acquisitions of written language. In his theoretical exposé, The Dynamics of written acquisition, Uppstad argues for a developmental view of written language acquisition that challenges existing views of language as an abstract static entity that use description of language systems and ignore the dynamic and developmental journey students take toward acquiring writing. He argues that language does not begin as a finished product and cannot be described only in those terms. To use another example: Uppstad would include all the developments related to learning to walk that might begin with sitting up and crawling and end with the ability to walk upright whereas the other school of thought would only describe walking in terms of the finished product. In a sense, this is reminiscent of the product and process orientations in writing research.

Uppstad argues for a relationship between oral and written language that is reflexive, each informing, building on and changing the other. This change involves the claim that a special mode of thinking is related to the act of speaking, and an analogous position has then been taken for writing, producing the notion of 'thinking for writing' (Strömqvist \& Verhoeven, 2004). The position of thinking-forwriting may in many ways serve as both an important theoretical basis and an operationalization of the view of reading and writing as a skill, by combining 'thought and language' into modes of action. This model, Uppstad claims, provides the best platform for maintaining dynamic perspectives in both research and education concerning written-language skills.

The second article, 'Written language skills and the notion of 'Iexicon,' was motivated by the need to search for a stronger empirical base for the scientific study of written language. The focus on behaviourism prevalent in mainstream theories derails the possibilities for the alternative understanding of lexicon that gives no $a$ priori predominance to spoken language over written, but opens the way to true empirical findings on how meaning is built up from both spoken and written language. To provide an empirical operationalization of the theory, Uppstad explores dyslexia because it deals very precisesly with the concrete interpretations of lexicon, phonology, and concept. He examines the research since it represents a close-up view of 
assumptions in the mainstream theories. What is offered is an alternative framework for considering the ways writing is conceptualized and operationalized.

In the final article of this issue, Erik Van Schooten and Kees De Glopper synthesize the results of four studies that concern attitudes towards reading fiction and the literary response of students in secondary education in the article entitled, Literary response and attitude toward reading fiction in secondary education: Trends and predictors. Concern over a perception that students were reading less resulted in new policies to actively promote reading in the Netherlands. The policies had two explicit aims: to change the reading habits of students in primary and secondary education resulting in students reading more and qualitatively better books, and to stimulate a positive attitude toward leisure reading. Stimulating a positive 'reading attitude' was assumed to result in more reading

From their intense and comprehensive study, they learned that attitude affects behaviour (that is, positive attitude to reading, for instance, results in more reading). They observed that 'affect' is the best predictor of intentions to read fiction, the direct precursor of actual reading behavior. This implies that the best way to stimulate students to read fiction is to experience reading fiction as pleasurable activity. Furthermore, they found a connection between vocabulary size and the amount of reading students engaged in. The data indicates that formal literary education appears to have a favorable effect on both literary response and reading attitude, and thus on reading behavior. Although 'text experiencing' shows the largest effects, 'literary history' and 'structural analysis' also seem beneficial for both reading attitude and literary response.

This study has relevance in many language and cultural contexts today where politicians and the media find ways to perpetuate precipitous declines in reading (usually test scores) as symptomatic of failures of the schools to adequately teach and prepare its future citizens. This needs to challenged by conducting research with students as this article demonstrates rather than on students (tests), as has traditionally been the case.

As editors, we are enthusiastic about the possibilities for this new phase of our development. This issue demonstrates clearly the possibilities, scope and need for further developments and research on language and literacy in the globalized and international world. Our interest in language and literature reflexively connects us.

For the editors, Mary Kooy, OISE/University of Toronto, Canada 